\title{
MOREIRA, UN ZARATHUSTRA CIMARRÓN Y MARXISTA
}

MOREIRA, A WILD, MARXIST ZARATHUSTRA

Rafael Arce

ORCID 0000-0003-3117-8816

\author{
Universidad Nacional del Litoral/CONICET \\ Santa Fe, Argentina
}

\begin{abstract}
Resumo
A obra de César Aira adquiriu sua forma reconhecível a partir da década de 1980 . Algumas de suas histórias juvenis, conhecidas muito mais tarde ou não publicadas até hoje, colocam questionamentos sobre o início da mesma. Este artigo propóe uma leitura de Moreira (escrito em 1972, editado em 1975 e conhecido a partir de 1981) como um texto que participa da vanguarda dos anos 60 e 70 e, ao mesmo tempo, vai além do seu programa, definindo alguns procedimentos que fazem forma á seu trabalho futuro. A violência formal de Moreira caracteriza os excessos de vanguarda da época e da juventude do escritor, com uma radicalidade que nunca mais se manifestará na obra posterior e cuja sublimação, conjeturamos, implica o magistério da obra de Borges.
\end{abstract}

Palavras-chave: vanguarda; violência política; transgressão; plágio; Osvaldo Lamborghini.

\section{Abstract}

César Aira's work acquired its distinctiveness from the 1980 s on. Some of the stories written in his youth, which were only known much later or are still unpublished to this day, pose some questions about the beginnings of his work. This article proposes a reading of Moreira (written in 1972, edited in 1975 and more widely known after 1981) as a text that forms parts of the avantgarde of the 60s and 70s and, at the same time, exceeds its boundaries, coining some procedures that will define Aira's future work. Moreira's formal violence reflects the avant-garde excesses of both the period and the writer's youth, with a

\section{Resumen}

La obra de César Aira ha adquirido su forma reconocible a partir de los ańos 80 . Algunos de sus relatos juveniles, conocidos mucho después o inéditos hasta el día de hoy, plantean ciertos interrogantes sobre los comienzos de la obra. Este artículo propone una lectura de Moreira (escrita en 1972 , editada en 1975 y conocida después de 1981) como un texto que participa de la vanguardia de los años 60-70 y, a la vez, desborda su programa, acuńando algunos procedimientos que definirán la obra futura. La violencia formal de Moreira caracteriza los excesos vanguardistas tanto de la época como de la juventud del escritor, con una radicalidad 
radicality that will never be manifested again in his later works and whose sublimation, we conjecture, implies the mastery of Borges's work.

Keywords: avant-garde; political violence; transgression; plagiarism; Osvaldo Lamborghini. que no volverá a manifestarse nunca en la obra posterior y cuya sublimación, conjeturamos, implica el magisterio de la obra de Borges.

Palabras claves: vanguardia; violencia política; transgresión; plagio; Osvaldo Lamborghini.

No sabemos bien cuándo comienza la obra de César Aira. Esta perplejidad es tanto más significativa por cuanto la magnitud del conjunto y la prolija datación que el escritor realiza al pie de la última página cuando termina una novela no debería plantearnos ningún problema con los inicios. Sin embargo, después de casi cincuenta años de carrera y más de cien novelas y novelitas, remontarnos a los comienzos no parece tan simple.

En 2002, la publicación de Las vueltas de Cesár Aira de Sandra Contreras sentó un fuerte precedente: la mayor relevancia de las fechas de escritura por sobre las fechas de publicación. Esta importancia radicaría, por un lado, en el problema de periodización que significó la edición de sus novelas inéditas a partir de la década del 90 y, por el otro, en la conjetura de una suerte de "diario de escritor" que el conjunto de novelas estaría entramando con esa huella que localiza el texto con precisión de fecha y lugar (CONTRERAS, 2002, p. 34). Para su lectura precursora, Contreras prefiere, de modo persuasivo, las fechas de escritura. No obstante, su lectura sitúa el acontecimiento de irrupción de la obra a comienzos de los años 80 , lo que resulta pertinente ya que no hay irrupción sin publicación y Aira comienza a publicar recién entonces, aunque venía escribiendo desde diez años atrás y había fechado, en esos años 70, por lo menos tres novelas que se conocerían solo después.

En 2008, la publicación de Osvaldo Lamborghini, una biografía de Ricardo Strafacce agregó una serie de problemas conexos. El fresco de época de la década del 70, en el que Lamborghini coincide con Aira, complementa el armado de Contreras del contexto de emergencia de la obra. Aunque la vida que se cuenta es la de Lamborghini, la figura de Aira es muy importante. Strafacce nos proporciona la imagen de un Aira poco conocido: un joven a la vez tímido y desenvuelto que a comienzos de los setenta permanece todavía inédito, aunque ya entonces hace circular entre escritores y críticos cercanos los manuscritos de sus novelas. Una de esas es Moreira, fechada en 1972 y cuya lectura provoca en Lamborghini una mezcla de asombro y perplejidad: “ipero mirá cómo escribe este piiiibe!, ipero mirá cómo escriiiibe” exclama (STRAFACCE, 2008, p. 307). En efecto, Aira "ni siquiera representaba los veinticuatro años que tenía" pero se comportaba con "suficiencia de veterano" 
(p. 306). Strafacce conjetura que Moreira habría sido la primera novela que Lamborghini leyó de su futuro discípulo y albacea (p. 306).

Hoy puede resultar sorprendente que Aira haya tenido dificultades para publicar en sus precoces inicios. La época facilitaba la edición de escritores nóveles, los sesenta-setenta habían instalado la idea de una literatura de vanguardia que podía escandalizar, sufrir censura (el célebre juicio a Nanina de Germán García que supuso la edición clandestina de El fiord de Lamborghini), ser leída por un público amplio de entendidos e, incluso, debido a sus temas escabrosos (el sexo, la violencia, la política), hasta vender una larga tirada. En efecto, en una época signada por la vanguardia de Literal, en la que se habían publicado textos como El fiord o El frasquito de Luis Gusmán, parece sorprendente el rechazo que provocó en algunos críticos y editores la juvenil novela de Aira (STRAFACCE, 2008, p. 340).

Las tres novelas que Contreras sitúa como fechadas en los años setenta son Las ovejas (1970), Moreira (1972) y Ema, la cautiva (1979). ¿Cuáles son, entonces, los comienzos de la obra? Las ovejas, escrita a los veintiún años, será publicada en 1984 junto a El vestido rosa por la editorial Ana Korn. Después de algunos rechazos, Moreira es aceptada por Horacio Achával, gerente comercial de Granica que tenía su pequeño sello, sugestivamente llamado Achával Solo (STRAFACCE, 2008, p. 340). Acepta entonces el manuscrito y en 1975 se estampa su pie de imprenta, pero los pliegos quedan guardados en un depósito, sin que lleguen a ser finalizados con el pegado de las tapas (p. 401). Moreira se conoce entonces después de Ema, la cautiva que en 1981 se convierte en la "opera prima" de Aira (p. 699).

A esta dificultad para establecer un comienzo (¿cuál es la primera novela?; ¿la primera fechada?; ¿la primera editada?; ¿la primera editada [y terminada con sus tapas] y enviada a las librerías?) podemos enmarañarlo aún más. Strafacce enumera una serie de novelas que Aira escribió en los setenta y que hasta hoy permanecen inéditas: Individual, Pensacola, Los cuatreros, Un puente, un gran puente, Danae, Zilio y El estúpido reflejo de la manzana en la ventana (p. 459 y p. 562). De Zilio, Strafacce reproduce un fragmento y El estúpido reflejo de la manzana en la ventana aparece mencionada en Las hijas de Hegel de Lamborghini.

Strafacce también nos cuenta que Aira leyó por primera vez El fiord en 1971 y que esa lectura le cambió la vida al joven escritor (p. 245) ${ }^{1}$. Sin embargo, no se explaya sobre el impacto que habría tenido esa mítica primera vez. Envuelto en los avatares de la amistad, el magisterio y la temprana elección del futuro albacea, esos pocos minutos en los que el joven Aira lee El fiord

1 "Fueron, en efecto, unos pocos minutos, pero bastaron para cambiarle la vida al incipiente escritor, a pesar de lo cual debían pasar casi dos años para que volviera a encontrarse con quien sería su maestro y amigo" (STRAFACCE, 2008, p. 245). 
pueden haberle cambiado la vida en el sentido de su vocación literaria. Pues el mismo capítulo nos cuenta la suculenta anécdota del encuentro de los dos escritores (o más bien el desencuentro), en el que un Aira estudiante de Letras, más interesado en el cine y en el rock que en la literatura, recibe el desdén de Lamborghini (sin que quede claro por qué) y solo gracias al tercero que los presenta (un personaje circunstancial) lee poco después El fiord (2008, p. 244-245). No obstante, la afirmación de Strafacce, enigmática (ien qué sentido le cambió la vida a Aira la lectura de El fiord?), podría sugerir algo más. Si su conjetura sobre esa primera lectura es exacta, Aira todavía no había escrito Moreira, algo que haría al año siguiente. ¿Puede estar sugiriendo -o permitiéndonos a nosotros intuir- una relación estrecha entre la lectura de $E l$ fiord y la escritura de Moreira? Es notable, en este sentido, los esfuerzos que realiza el biógrafo por subrayar la excepcionalidad de Moreira en un contexto que, sin embargo, no parece serle del todo ajeno.

En nuestros días, una relectura de Moreira, una vez estabilizada cierta imagen de su obra, puede acaso desconcertar. Los rasgos que nos acostumbramos a considerar como definidores de lo "airiano" (amenidad del relato, fuga hacia adelante, velocidad, prosa transparente, felicidad como tonalidad afectiva, imaginación desbordante, invención descabellada) no parecen cuadrarle a Moreira. Es una novela de lectura difícil, tal vez desagradable, que despierta suspicacia y de la que, como ninguna otra de Aira, uno puede preguntarse si no se trata de una gran tomadura de pelo, un chiste sofisticado, una agachada seudo-vanguardista. Sucede que la codificación de la obra hace que esos primeros textos puedan interpretarse a la luz retrospectiva de un gran trabajo de lectura crítica que ha generalizado sus hipótesis. La misma Contreras incluye Las ovejas y Moreira en su corpus utilizando claves que la obra posterior le permiten estabilizar: el darwinismo airiano en Las ovejas (CONTRERAS, 2002, p. 50) y el ejercicio de traducción borgiano de Juan Moreira (CONTRERAS, 2002, p. 125). Las dos novelas situarían así el origen de la obra en Borges ${ }^{2}$.

En este trabajo, propondremos una lectura de Moreira que, aunque no desdeña las claves que proporciona la obra, intenta desprenderse un poco de ellas. Se trata de restituirle a esta novela una extrañeza que la codificación de la obra le ha quitado o, por lo menos, disimulado. Tal extrañeza, quisiéramos proponer, especula sobre una posibilidad acaso incomprobable: un Aira

\footnotetext{
2 En un trabajo muy posterior a su libro, Contreras sintetiza este doble origen en la "estilización" de Las ovejas, que sería una variación del nominalismo borgiano, y en la apropiación del imaginario popular de Moreira: "en el origen de la ficción de Aira está, notoriamente, el mundo de Borges -el nominalismo y el Gutiérrez de Borges, lo culto y lo popular, la filosofía y el puñal-, que la ficción de origen de Aira pasa por ese 'rito de iniciación' del escritor argentino que es pasar por Borges en el comienzo, en la juventud" (CONTRERAS, 2013, p. 194). Agreguemos que el plagio, común a las dos primeras novelas, el plagio de Borges y el plagio como estrategia borgiana, subrayan el carácter iniciático de ese rito.
} 
setentista, cercano a la poética de Literal, cuya obra inicial, sustraída en su mayor parte a la publicación, podría haberlo adscripto a una estética de la novela definida por esa vanguardia. Esta lectura la hace posible la misma Contreras: el Moreira de Aira, mito de origen de su concepto de "literatura mala”, es un Moreira que

convoca inmediatamente el contexto de la vanguardia estética y política de los 70. Están allí, articulados con los discursos de la transgresión (los saberes políticos, psicoanalíticos, teórico literarios de los años 60), la violencia política y la violencia formal (CONTRERAS, 2002, p. 125).

La clave de nuestra lectura la proporciona el mismo Aira en su ensayo sobre Borges, "La cifra". Para Aira, la obra de Borges consta de dos momentos (no necesariamente temporales): el de su juventud vanguardista, en el que participó de la empresa colectiva de sus contemporáneos (la vanguardia de los ańos veinte), y el de su viraje individual, en el que reniega de su vanguardismo juvenil, abomina de algunos de sus primeros libros y empieza de nuevo (AIRA, 1999). Aira afirma que esta duplicidad constituye una dialéctica no resuelta que sigue siendo el misterio de su obra, motivo por el cual, si bien posee una dimensión temporal (un joven Borges, de vanguardia, y un Borges maduro, "clásico"), por otro lado, puede considerársela constitutiva, originaria.

Podríamos aplicar a Aira la misma tesis. Pues no es Moreira tan diferente de los textos de la vanguardia de los 60-70. Moreira no sólo alude al materialismo y al marxismo, convocando una discusión común en su época, sino que su materialidad abyecta, corporal y sexual, lamborghiniana, caracteriza su versión del gaucho malo de Gutiérrez. El estilo exasperado y hasta urticante, ni siquiera atemperado por la música de Lamborghini, con toda la violencia de éste, pero sin la cadencia poética que hace al exceso digerible, lo hace no desentonar de sus contemporáneos. Por el contrario, puede considerarse un ejercicio cercano a las ideas de Literal: una estética anti-realista y anti-representativa (con su correlativo énfasis en el concepto de escritura barthesiano) y una sexualización de los textos (y su correlativa alusión al psicoanálisis) (PELLER, 2016, p. 175). Como muchas novelas de los escritores relacionados con esa vanguardia, Moreira hace alusiones a Freud, a Lacan, a Joyce, a Shakespeare, a Lautréamont, a Duchamp, a Platón, a Marx, a Hegel, a Saussure, al telquelismo y al textualismo de la época, en una "hibridación" de ficción y de teoría, y un generalizado trabajo con el "injerto" (PELLER, 2016, p. 295-206).

Pero, ¿en qué sentido la novela de Aira se diferencia? Podría conjeturarse que esas alusiones, lejos de integrarse en la textura de la novela, se montan en un collage cuyo efecto es una especie de cinismo: "El sonido de la corriente 
lo 'adormecía de felicidad'; como a Joyce; operaciones subjetivas y objetivas. Paisajes" (AIRA, 1975, p. 7). "El Phallus erecto de nuevo, se lo metió entre sus negros carreteles" (p. 40). "Aquí salta una forma desconocida del uno, el Un del Unbewusste. Digamos que el límite del Unbewusste es el Unbegriff-no inconcepto, sino concepto de la falta" (p. 55). "Nos sentíamos tan extraños como Hamlet representando el papel de Ofelia la noche de bodas" (p. 59). Los fragmentos podrían multiplicarse: la biblioteca de un escritor de los setenta se exhibe no con petulancia (como se dijo de las novelas de García) sino con ironía.

Para Strafacce, Moreira no se contentaba con arremeter contra las convenciones del realismo y el populismo de la literatura comprometida, tal como lo proponían los textos de la constelación Literal, sino que "escribía como si esas convenciones no existieran, como si no hubieran existido nunca" (p. 306). Sin embargo, Moreira es una novela cuya factura pertenece a esa empresa colectiva (la de la vanguardia de los sesenta-setenta), pero cuya irrisión incluye también a esa "literatura prologada" (PELLER, 2016, p. 179) de la que se mofaron sus detractores y es en este sentido que hablamos de cinismo. La posición cínica del texto es el efecto de la yuxtaposición de alusiones hiper-literarias en el pastiche humorístico y soez de la prosa, procedimiento que también podemos considerar lamborghiniano, aunque más característico de algunos de sus relatos póstumos (y no tanto de las dos primeras novelas). Este choque de heterogéneos (Moreira filosofando entre animales, alusiones a la vulgata psicoanalítica en una charla de lupanar, citas de grandes textos de la literatura occidental entre malas palabras y escenas pornográficas, mezcla de un estilo sofisticado con entonaciones criollistas) produce el mismo efecto cínico que el final de Las ovejas, cuando el nombre de una, "Moussy", reemplaza a "Berkeley" y en la última línea "las ovejas" reemplazan a "David Hume" (AIRA, 1984, p. 151-152).

Si Aira hizo lo que afirma que Borges hizo, la diferencia salta a la vista: él no publicó libros de los que tuvo que renegar. Moreira de modo ostensible, aunque también Las ovejas, con la que comparte algunos procedimientos claves, manifiesta una vocación de ruptura cuya espectacularidad tiene la violencia de los comienzos y el desparpajo de la vanguardia juvenil. Esa espectacularidad la volvió, para el espíritu de la época, poco legible, más aún que las de la constelación Literal, cuya factura novelesca, a pesar de lo experimental, permite reconocerlas como tal. No deja de ser significativo que ni Las ovejas ni Moreira hayan vuelto a ser editadas. Fechada en 1979, Ema, la cautiva, salida de la pampa airiana que forjan las novelas anteriores, cristaliza como la primera "madura". Cuando se publica Ema, la cautiva, Aira tiene treinta y tres años. Ya no es un joven vanguardista (pero, ¿acaso lo fue alguna vez?). Es un escritor maduro que viene de publicar "Novela 
argentina: nada más que una idea”, su célebre ataque a la novela argentina de los setenta y a Respiración Artificial de Ricardo Piglia, que tanto revuelo provocó. No tiene textos de ficción publicados, pero ha rubricado su propio manifiesto, con la virulencia y la apuesta al futuro que caracteriza su retórica. No está "experimentando" nada. Sabe muy bien lo que hace. Y, aunque no sepa lo que hace, sabe muy bien lo que no hace, lo que no quiere hacer. Es como si Aira eligiera su comienzo. No su origen, porque del origen podemos hacer la genealogía retrospectivamente, sino su mero inicio, que hoy podemos reconocer como "airiano" en su sentido más propio. Ese comienzo permite a Contreras hablar de la "emergencia" de la obra y del contexto que viene a reducir a la nada. Pero sus dos primeras novelas quedan como eslabones sueltos, emparentados con la obra pero misteriosamente separados.

La vida nueva, de 2007, en la que se recupera la figura de Horacio Achával, novela el incidente de esa malograda primera publicación:

[Achával], aun siendo un hombre de larga militancia izquierdista y gran compromiso político y social, supo apreciar el soplo fresco de irreverencia que representaba lo mío y que no era otra cosa, según él, que la libertad intrínseca de la literatura, antídoto necesario a la seriedad o solemne empaque, ya francamente estalinista, que estaban tomando las ciencias sociales (AIRA, 2007, p. 11).

El final de La vida nueva proporciona un sugestivo apoyo a la conjetura de que Moreira permaneció, para la obra airiana, en potencia, como aquello que pudo haber sido:

No me llegó la noticia de su muerte, y yo preferí no averiguar. De algún modo extraño, lo sentía vivo, un fantasma amable, protector, presidiendo mi juventud, o la juventud del escritor que no habia sido, un mojón que marcaba el comienzo de mi vieja vida nueva (AIRA, 2007, p. 77, subrayado nuestro).

La concepción material de la lectura es para el Aira de los setenta el pesado lastre de los saberes humanos y sociales que, fundamentando una posición política comprometida y una concepción material del arte y la literatura, imponen una visión única de los fenómenos, un tratamiento "serio" del material ${ }^{3}$. En este sentido, Moreira no solo rechazaría el compromiso

3 La exhortación de Moreira, "Sean marxistas" (AIRA, 1975, p. 61), parece mofarse de ese compromiso político de la época. Pero los sarcasmos de Aira no siempre son tan fáciles de establecer. Para Nicolás Suárez, que hace una interesante relación entre Moreira y Lamborghini (la única de la que tenemos noticia), la exhortación, por el contrario, puede ser leída como una metáfora: "ser marxista es ser vanguardista o revolucionario en el arte, en el sentido en que la literatura sería revolucionaria porque 'da güelta todo y eso es lo que se llama un tiro de desgracia" (SUÁREZ, 2014-2015, p. 231). Esta sugestiva tesis podría dar sentido a una frase de Aira de "Ars narrativa" que también parece el típico chiste con el que el escritor 
político que desdeñaban sus contemporáneos vanguardistas, sino también la práctica barthesiana de la escritura que estos mismos compañeros proponían estratégicamente, imbuidos de teoría. En este rechazo inicial, la sexualidad violenta y la violencia sexual se subliman, podríamos decir, en un pudor borgiano: la virginidad de las ovejas contrasta con la potencia fálica de un Moreira tan marxista como freudiano. Aunque novelas como Un sueño realizado, Yo era una mujer casada y El santo tengan escenas sexuales y también violentas, no pueden ser emparentadas de ningún modo con la radicalidad de Moreira. Algunas pistas permiten conjeturar que la escena de Moreira con la prostituta cita a El fiord:

Una observación, una superficie; ese vidrio sobre el que restallaban los latigazos. [...]

La muchacha cagaba.

[...]

En efecto, la panza bien redonda de Felissa se estremecía, y algo le bajaba untuosamente.

[...]

El nińo era negro. Lo llamaron La Caperucita porque nació velado con una capucha blanca.

[...]

Nació con todos los dientes y no bien hubo sido dado a luz le mordió a la madre las piernas, le dejó marcas ensangrentadas (p. 33-35).

Josefina Ludmer considera que esta novela directamente "funda la vanguardia literaria de los años setenta" (LUDMER, 2011, p. 253). Los "cuentos de Moreira" retornarían cada vez como predicamento anti-estatal. Si El fiord es una fábula sobre la erección sangrienta del Estado, es también contra lo estatal que se desata la furia de Moreira. En la novela de Gutiérrez, una y otra vez el gaucho afirma que lo persigue la Justicia, refiriéndose de ese modo abstracto a los mecanismos policiales estatales. El moreirismo airiano participaría de una pulsión antiestatalista en la que la política se sexualiza: el héroe fálico se enfrenta a la erección cefálica del Estado, la famosa daga de Moreira se vuelve símbolo psicoanalítico y político. Pero también el Moreira de Aira es lamborghiniano porque desborda el falocentrismo marxista y freudiano de la época, transexualizándose:

nos ha acostumbrado a identificar su estilo: "Yo busqué las armas en Leibniz y terminé encontrándolas en el marxismo" (AIRA, 2021, p. 182). Haremos, en las conclusiones, una interpretación distinta, aunque cercana a la de Suárez, de la exhortación. 
¡Tenía tetas! Se las decoraba con estampillas, con la lengüita les mojaba la goma... (AIRA, 1975, p. 30).

Lo miramos. Sus senos, ligeramente protuberantes, perecían los de una niña. Rosados; los pezones y la aureola mamaria oscuros. Latía debajo, como lo habíamos escuchado dentro del cuerpo de nuestras madres (AIRA, 1975, p. 54).

No habría que desdeñar, en este contexto, que El informe de Brodie de Borges se publica en 1970. Es un libro que retoma la figura de Moreira o, haciendo abstracción del cuerpo del héroe, retoma la tradición del moreirismo como predicamento anti-estatalista: Juan Muraña, por citar uno de los varios cuentos de cuchilleros, una alucinación o un fantasma, hace la justicia que el Estado no provee. Asimismo, aunque en el célebre prólogo se haya subrayado el desentendimiento respecto de la política como forma de rechazo a ese "estanilismo" del que habla La vida nueva (la demanda a los escritores de compromiso político), también puede considerarse la frase "con el tiempo mereceremos que no haya gobiernos" (BORGES, 2007, p. 457) como una exhortación curiosamente anarquista $y$, en este sentido, coherente con el moreirismo del libro. El Moreira de Aira es una especie de fantasma o de muerto-vivo: existe solo como retorno del viejo mito. No es un héroe de acción, sino de pensamiento.

En esa obra que no fue (o en ese escritor que Aira no fue), hubo también una opción por una imaginación controlada, por un "sueño dirigido" (BORGES, 2007, p. 457) que encauzó el surrealismo libre de Moreira, aparente escritura automática (habría que decir más bien "relato automático") que Strafacce interpreta como gesto radical ("escribe como si esas convenciones no hubieran existido nunca"). En su ensayo sobre Alejandra Pizarnik, Aira entiende que la poeta invierte el procedimiento surrealista, en un ejercicio paradójico, utilizando el procedimiento (la escritura automática) para escribir "buenos poemas" (cuando la prédica surrealista consistía en desentenderse del resultado). La subjetividad pizarnikeana se "descarga" en esos personajes oscuros que aparecen en los poemas, evacuación del "sujeto patético" (AIRA, 1999) que permite un control (o, dicho con más precisión, una supervisión) de la escritura automática (AIRA, 2004, p. 9-30). Cuando Aira lee a Lamborghini, hace algo parecido: traduce la escritura automática al procedimiento de escritura frase-por-frase, de modo paradigmático en "La novia del gendarme", segundo capítulo de Las hijas de Hegel (AIRA, 1988, p. 11). Moreira es la novela de Aira que más cerca está de ese método lamborghiniano de la frase-por-frase: tal vez sea, sin más, la única. En este sentido, puede aplicarse también a Aira lo que él dice de ese "empezar de nuevo" de Borges: un recomienzo en el que el rechazo del programa colectivo implica una recuperación del yo, pero de un yo atenuado (en el caso de Pizarnik, un yo desplazado). El nombre 
propio del autor aparece tres veces en Moreira, yuxtapuesto sin ningún sentido perceptible (p. 33, p. 49 y p. 57). Así como Ludmer vio en El fiord un anagrama de Freud castellanizado, así también podríamos pensar en un Mor-aira (VILLANUEVA, 2005, p. 1175).

Si volvemos a las referencias a El fiord, se verá que se encuentran montadas en un continuo que yuxtapone frases en apariencia incoherentes, cuyo encastre se realiza forzadamente en el hilo de la historia. No es que el relato haya sido escrito así, sino que los párrafos que arman la historia parecen redactados mediante el procedimiento de la frase-por-frase. Este recurso injerta alusiones literarias sofisticadas con palabras soeces y entonaciones del registro criollista. Ahora podemos leer Moreira a través del prisma lamborghiniano: se trata de una operación que desborda la posible influencia que El fiord haya tenido en el joven escritor. Como en Pizarnik, Aira purifica la escritura automática de ingenuidades utópicas: el método de la frase-por-frase lamborghiniano es esa purificación, un azar controlado, una yuxtaposición deliberada.

La pampa abstracta, vaciada en Las ovejas, se convierte en Moreira en un escenario, un espacio artificial, donde el paisaje de la puesta de sol es una pintura y la escena de conversación gauchesca es irrealizada por las referencias literarias hipercultas. Es el espacio de la fábula airiana o, mejor, de su mecanismo: contar la historia, volver a contar el cuento. Estas historias, como espectros, evocan el Manifiesto comunista: "Unas novelas recorren las pampas, asustando a sus contemporáneos, pues arrastran consigo los nombres y las imágenes de los difuntos" (p. 10). Pero la pampa es también el espacio del pensamiento (el paraje, en las dos novelas, se llama justamente El Pensamiento): las ovejas descubren el idealismo, mientras que Moreira reflexiona sobre la muerte. La pampa "llena", exuberante, de Ema, la cautiva y de La liebre, pasa no obstante por este momento de vaciado, en el que se hiperboliza la desertificación simbólica que operaron los clásicos del XIX: la pampa de Las ovejas es como un suelo selenita del que hasta la vida humana se ha ausentado y la de Moreira es un espacio de fantasmagorías, sueńos, alucinaciones.

Nos hemos acostumbrado a considerar que el vanguardismo airiano no está en los juegos con la temporalidad que caracterizan a la gran novela modernista del siglo XX. En efecto, sus relatos empiezan y terminan con nitidez. Moreira, por el contrario, presenta una coalescencia temporal inédita en la obra, mezclando tres tiempos: el contemporáneo a la novela, en el que se hacen curiosas referencias a la coyuntura política ("la administración militar ha querido premiar con ese gesto la solidaridad de los acaudalados terratenientes de la zona para con la Junta de Comandantes" [p. 15]); el del relato de la muerte de Moreira que le hace Julián Andrade a Paspartú; y el de la historia de la muerte de Moreira. Estos tres tiempos están mezclados 
desde los dos primeros capítulos. A la descripción del escenario de la fábula, en el que se contará una historia en un ambiente oriental (el crespúsculo es el Oriente y la historia ya la conocemos: es una leyenda, un cuento que no nos cansamos de volver a oír), le sucede un tiempo extrańamente contemporáneo (un drugstore, aviones, un Club de Golf, refrescos), en el que Moreira aparece como un fenómeno óptico: un ser de un centímetro que se va agrandando, observado por un telescopio. Como si se tradujera la escena de "El fin" de Borges a los prismas duchampianos que Contreras lee tan bien: esa mirada microscópica, naturalista, es también la del narrador a su héroe, que se agiganta por un efecto de perspectiva.

Este efecto es también temporal: los diferentes tiempos se acercan, se empastan, en una misma fábula. El drugstore del segundo capítulo, el que introduce el tiempo contemporáneo, se hibrida en el tercero con la pulpería el ABC, donde Moreira se encuentra con la prostituta. El relato adquiere, a partir de ese tercer capítulo, un nacarado onírico en el que los principios de identidad y de causalidad no existen, y en el que tampoco la muerte parece existir: los personajes cambian de nombre (como en El fiord), de identidad (una de las hijas del dueño del drugstore-pulpería se vuelve la prostituta del $\mathrm{ABC}$ y después la esposa del pulpero), la trama se deshilacha, hay asesinatos y resurrecciones. Si esta novela es la más cercana al lamborghiniano frasepor-frase, también lo es de un surrealismo "puro": una fábula que remeda la experiencia de los sueños. No hay antes ni después, porque el tiempo del héroe, el de la leyenda, es el tiempo fuera del tiempo del mito, de la literatura. Podríamos decir también que, lejos de utilizar el psicoanálisis como saber teórico injertado o matriz ficcional, Moreira ensaya directamente un relato onírico, puro presente mental del autor ${ }^{4}$, contestando al saber más prestigiado por la constelación Literal. A medida que se avanza en la lectura, el héroe va adquiriendo "dimensiones colosales", se va "agigantando" en la imaginación de los paisanos, como se agranda el gauchito de un centímetro con el uso del telescopio. Pero también el Moreira de Aira se transforma en un monstruo gigantesco, colosal, inhumano, que pelea menos como un gaucho que como un superhéroe.

Contreras afirma que Moreira es una traducción de la novela de Eduardo Gutiérrez al Hormiga Negra del mismo autor, en una operación de puesta en escritura de la opción borgiana: el estilo vil de Hormiga Negra depura a Juan Moreira de eso que repugnaba a Borges, el romanticismo del héroe y su destino trágico (CONTRERAS, 2002, p. 125). Pero ese "estilo vil" también

4 Dice Aira a propósito de Copi: "Si nos atenemos a la primera definición que di (la novela es lo que pasa) los surrealistas escribieron las únicas novelas en estado puro, mutiladas de pasado, pura exposición de los acontecimientos del presente mental de su autor" (AIRA, 2003, p. 55). Volveremos sobre el final a las concepciones airianas expuestas en este ensayo. 
puede considerarse en su prosapia lamborghiniana: Nicolás Rosa habla de "escritura" (o de "letra") vil (ROSA, 2006, p. 109-116).

Ahora bien, puede conjeturarse además que Aira encuentra en "la novela mala" del siglo XIX no solo una preferencia por la "literatura mala", sino también la invención misma de la inverosimilitud: como un ready-made latente en los pliegues del comienzo, el pastiche seudo-Literal ya ha encontrado el tesoro escondido de la inverosimilitud. En efecto, ahora podemos leer Juan Moreira como una novela cuyo gran mérito es poder continuar (valor del folletín, dicho sea de paso, algo de lo que la literatura de Aira no tendrá nada). Hoy podemos leerla como una novela que, partiendo de un verosímil realista, a medida que avanza, va acumulando escenas de inverosimilitud, cada vez más desopilantes, y la habilidad de Gutiérrez, un escritor decididamente malo, que se la pasa explicando el sentido de todas las acciones y escenas, sin dejarle nada al lector, consiste en salvar esas inverosimilitudes, aun a costa de otras más graves. Moreira es una lectura airiana de la novela de Gutiérrez en el sentido del object trouvé: encuentra, en la novela mala de la literatura argentina del siglo XIX, uno de sus procedimientos claves.

Moreira es un gaucho bueno y bello que cae en desgracia por las injusticias que ya había denunciado Martín Fierro. Inicia entonces un escape y una venganza que muy pronto dejan de ser motivo, puesto que decide abandonar a su mujer y a su hijo para no exponerlos a la revancha de sus enemigos. La historia podría haber concluido ahí, pero Moreira reinicia la huida, esta vez perpetua, en la que va ganando su fama a lo largo de toda la provincia de Buenos Aires, peleando con partidas y con gauchos que se las dan de guapos y buscan su propia gloria. Suspirando todo el tiempo por el terruño perdido y por su triste destino (lo que da a la novela ese tono lastimero que repugnaba a Borges y que nos repugna a nosotros), Moreira manifiesta su deseo de morir, el sinsentido de su vida y de la existencia en general, la imposibilidad de luchar contra una estatalidad monstruosa e injusta.

Pero he aquí el gran truco folletinesco de Gutiérrez. Moreira no puede dejarse matar, porque, aunque su vida carece de sentido, conserva su orgullo viril de gaucho y su honor. Pero también pelea por "lujo", por derroche, es decir, sin motivo, haciendo de la lucha no un medio, sino un fin en sí mismo. Cuando Julián Andrade le reprocha lo que considera un exceso de exposición, una tentación inútil de que lo maten o lo prendan, Moreira responde:

Hasta ahora solo he peleado con la justicia por puro lujo, deseando que me mataran para concluir de penar de una vez. He peleado fuerte para mostrarles que no soy candil que se apaga de un soplido, pero las circunstancias han cambiado. Ahora he de pelear para defender mi vida, porque quiero vivir para los que me han insultado en mi desgracia, aprovechándose de una mujer desvalida (GUTIÉRREZ, 2011, p. 175). 
Hay una alternancia en verdad ocurrente para que el héroe de la novela vaya pasando de motivo en motivo, para morir, para vivir, para morir "a su modo", para que lo maten. Primero pelea para vengarse del usurero. Después, mata para vengarse del juez. Sigue peleando con la esperanza de sobrevivir para estar de nuevo con su familia, pero muy pronto comprende que debe abandonarla para salvarla. Entonces pelea para vengar a los que han mancillado a su mujer. Y cuando parece que tiene rienda suelta para morir, debe encontrar otros motivos para sobrevivir: "Moreira, pues, como decía, no peleaba por defender la vida; deseaba que lo matasen, pero que lo matasen como él debía morir, rodeado de cadáveres policianos y de oficiales de partida" (p. 290).

Desea, entonces, morir acometiendo, pero como es el mejor peleador de su época, ese deseo parece imposible de cumplir. Las situaciones límites a las que lo va exponiendo la historia la vuelven una y otra vez inverosímil, y las razones para no morir (y que se termine la novela), aunque se pelee para morir (y sobreviva la historia), se van volviendo cada vez más bizarras. Aira encuentra entonces en Juan Moreira o, mejor, Moreira encuentra en la novela de Gutiérrez los procedimientos de "verosimilización" y de "continuo": verosimilizar es invertir el código del relato realista, operando siempre una dación de sentido a lo que no lo tiene (como en el primer cadáver exquisito del Surrealismo en Alejandra Pizarnik) o creando sentido entre dos elementos heterogéneos (los billetes falsos y la escritura del poema de vanguardia en Varamo: como quien dice dar sentido al paraguas y la máquina de coser). El continuo es un procedimiento más complejo o es un conjunto de procedimientos o de derivas de un mismo procedimiento. En Juan Moreira, es la mera posibilidad de continuar la historia. No se trata de un continuo de escritura (escritura automática del surrealismo, frase-por-frase lamborghiniano), sino de historia, de aventura, de fábula.

Julián Andrade no solo relata a Paspartú (pass-par-tout) la muerte de Moreira, sino también los discursos que pronuncia en el trance previo, cuando los paisanos lo instan a huir y él prefiere esperar a la partida. En la novela de Gutiérrez, Moreira habla demasiado: "Esto era lo más hinchapelotas de Juan: cuando empezaba con las anécdotas, ¡ufa! (AIRA, 1975, p. 32). Cuenta historias, moraliza, teatraliza: se vuelve Juan Blanco (personaje que Lamborghini travestirá en Juana Blanco), juega, se divierte, se "da lujos", derrocha coraje y recursos físicos (su vista de águila, su resistencia, su fuerza, su velocidad). La escena de los discursos podría estar haciendo irrisión de la perorata política propia de los años setenta. Aira la transmuta con relatos de la filosofía: Moreira es una especie de Zarathustra, pero también de Sócrates. Como el personaje nietzscheano, parlamenta con sus animales, que desde Las ovejas se han multiplicado, poblando el Pensamiento como el espacio 
imaginario de la ficción airiana. Como "Funes el memorioso", el Moreira airiano es un "Zarathustra cimarrón y vernáculo" (BORGES, 2007, p. 583). Graciela Montaldo habla de una "vanguardia bizarra" (MONTALDO, 1998, p. 12) en relación con Aira, en contraste con el criollismo urbano de vanguardia borgiano. También podríamos decir que ese Aira setentista habría encarnado una vanguardia cimarrona 5 .

En sus dos primeras novelas, Aira utiliza el plagio como procedimiento, algo que nunca volverá a practicar después, por lo menos hasta donde sabemos. Son dos los fragmentos que copia literalmente de la novela de Gutiérrez. Pero Juan Moreira no es el único texto plagiado. El Moreira airiano es una mezcla de Zarathustra y de Sócrates. En efecto, hay varios fragmentos en los que se retoman diálogos platónicos, por ejemplo, una reescritura, o versión, del famoso mito de la caverna que está en La república (AIRA, 1975, p. 57 58). El plagio platónico se realiza con Fedón. Si en Las ovejas se examinaba el idealismo con el prisma borgiano, resulta interesante esta reescritura de escenas de los diálogos platónicos en un texto que hace irrisión del materialismo como posición filosófica dominante en la época.

Aira pone en relación el plagio con la reescritura, siguiendo las lecciones de Borges. Aunque la cita sea literal, cortar y pegar, hacer del texto un collage, ya es reescribir. El plagio es el grado cero de ready-made literario: plagiar es firmar lo ya hecho y se lo firma desde que se lo monta en un collage. Por lo demás, la misma idea de retomar un mito argentino archiconocido, popular, hace del personaje un ready-made. En el collage que es la novela de Aira, los fragmentos de Gutiérrez, novela folletinesca, se vuelven "artísticos” por su recolocación. Si la copia exacta es ya una suerte de reescritura, la variación mínima (como en el final de Las ovejas) es el pasaje del plagio a la reescritura. Los fragmentos plagiados de la novela de Gutiérrez operan este paso. En el primero, se trata de la descripción que se hace de Moreira cuando los personajes lo observan, pequeño, a través de un telescopio:

Era un paisano hermoso, que vestía con lujo deslumbrador: con un traje que no era de ciudad ni de campo, siendo mezcla de los dos.

Su pequeño pie estaba calzado con una rica bota granadera, de cuero de lobo, que sujetaba el empeine con una lujosa espuela de plata con incrustaciones de oro.

5 Dice Strafacce que Moreira, comparada con Los cuatreros, era mucho más breve "pero no menos cimarrona” (p. 306). Al final de la novela, hay una referencia a la memoria de Moreira que parece evocar no solo a Funes, sino también conectar con la teoría de la reminiscencia desperdigada en los pastiches platónicos que analizaremos más abajo: "Mucho se ha hablado de la memoria de Moreira, pero no todo ha sido dicho. Ni una pequeńa parte. No pretendo decirlo yo, pues ningún humano es capaz de pensar en ella; ni quien escribe ni sus lectores pueden llegar a hacerse una idea de la gran memoria de nuestro héroe" (AIRA, 1975, p. 80). 
Llevaba bombacha de casimir negro, sujeta a la cintura por un tirador de charol, abotonado con monedas de oro y adornado con pequeñas monedas de plata, en una cantidad tal, que apenas se podía adivinar, por los pequeños claros, la clase de cuero de que estaba hecho ese tirador.

Por la parte delantera de éste asomaban las culatas de dos enormes trabucos de bronce y las de dos pistolas pequeńas, pero de gran calibre y sistema moderno. Detrás, asomando por ambos costados, aquel hombre traía una daga en vaina de plata, con una $S$ de oro cincelado, que despertaba envidia en cuantos la veían.

El traje estaba completado por una chaqueta de casimir azul oscuro y sombrero de anchas alas que llevaba un poco a la nuca, dejando descubierta una frente juvenil y arrogante, iluminada por la expresión de dos ojos negrísimos de extraordinaria fijeza, que miraban con una altivez irresistible (AIRA, 1975, p. 17-18).

Los primeros cuatro párrafos están copiados tal cual y el quinto tiene una sola supresión. Aira toma la descripción de la entrega "El guapo Juan Blanco" en la que Moreira adopta una identidad falsa para crear una especie de juego de máscaras mediante el que puede escuchar hablar de sí mismo como si fuera otro y, al final, revelar su verdadera identidad. La única modificación de este quinto párrafo es la supresión del nombre propio: “...sombrero de anchas alas que Juan Blanco llevaba...” escribe Gutiérrez. El recorte se realiza, entonces, sobre una escena de Juan Moreira especialmente artificial, en la que el protagonista asume teatralmente su personaje de guapo y en donde el "lujo" del matar se transforma en un lujo indumentario, refinamiento femenino, "hermafrodita" (LUDMER, 2011, p. 243), suerte de anticipación del travestismo del Moreira airiano y de la Juana Blanco lamborghiniana.

El otro fragmento es muy breve y parece insignificante, pero es interesante porque mezcla el plagio con la reescritura de la escena. Se lee en Moreira:

El ABC era una casa de negocio donde se comía, se bebía y donde se despachaban hermosas mujeres, una de las cuales había merecido las más finas atenciones por parte de Moreira. Mientras este se desnudaba en la oscuridad de la pequeña habitación, la muchacha le contaba los preparativos de la policía para prenderlo, a lo que el gaucho respondía con una sonrisa despectiva (p. 32).

\section{Y Juan Moreira:}

La Estrella era una casa de negocio donde se comía, se bebía y donde se despachaban hermosas mujeres, una de las cuales había merecido las más finas atenciones por parte de Moreira. 
[...]

Enseguida se desnudó y se acostó, mientras Laura a su lado le contaba los preparativos para prenderlo y las ganas que le tenían (p. 292).

La entrega del folletín es "Jaque mate", donde se detiene particularmente la versión airiana, pues recoge los episodios del encuentro con la prostituta y la pelea con la partida. En la secuencia de Gutiérrez, Moreira y Julián Andrade se quedan dormidos antes de la emboscada de la policía. En la novela de Aira, las escenas sexuales se yuxtaponen a momentos estrambóticos, durante los cuales Moreira descubre un proyector de cine y se alude a las máquinas solteras de Duchamp. Mientras el personaje del folletín duerme, en la novela de Aira parece deambular por un sueño ajeno, una fantasmagoría de ese César Aira al que se alude, por su nombre o por su apellido, en tres momentos:

El ejercicio lo ponía soñador. Iiiiic iiiic. Entre las moscas se había colado (¿por dónde? la pieza no tenía ventanas) un pájaro gris del tamańo de un dado; chillaba con una sola nota, como un insecto. ¿Qué me estará diciendo? Pensaba Aira (p. 33).

La secuencia plagiada del Fedón se monta en el segundo capítulo. Como en la secuencia de Juan Blanco, la identidad permanece oculta hasta el final del capítulo, en el que se presenta a la concurrencia, primero en lengua griega (la frase está escrita con esos caracteres) que se "traduce" al español: "-Yo soy Juan Moreira” (p. 27). No obstante, el fragmento de Fedón ya anticipa el momento de la novela de Gutiérrez en el que se concentrará la historia: la muerte de Moreira. Ahora bien, aunque la novela se concentre en un solo episodio, ese episodio, a través del prisma del texto platónico, se vuelve motivo. Recordemos que Fedón es el diálogo en el que el discípulo que da título cuenta a otro las horas previas a la muerte de Sócrates. El padre de la metafísica occidental, como no podía ser de otro modo, dialoga sobre varios temas concurrentes a ese acontecimiento, uno de los cuales es la supervivencia del alma después de la muerte del cuerpo. En el primer capítulo de Moreira, en el que Paspartú se encuentra con Julián Andrade, Aira evoca el comienzo del diálogo platónico: "Paspartú interrogó a su amigo. ¿Había estado él presente el día de la muerte de Moreira?" (p. 13). El diálogo comienza con la pregunta de Equécrates a Fedón: “¿Estabas junto a Sócrates tú mismo aquel día en que bebió el veneno en la prisión, o alguien te contó lo que pasó?” (PLATÓN, 1971, p. 77) ${ }^{6}$.

6 Citamos la traducción del profesor Conrado Eggers Lan, publicada en Eudeba en 1970, común entre los estudiantes de Filosofía y Letras de entonces. Como quedará claro más abajo, es la que Aira manejó. 
En Fedón, la inminencia de la muerte de Sócrates lleva a la reflexión sobre la práctica filosófica como una preparación para tener una "buena muerte": para el maestro de Platón, la muerte es el gran motivo del filósofo durante toda su vida y no sólo en la inminencia del fin. Moreira se detiene en el capítulo de la muerte del héroe en el folletín, pero el prisma del diálogo platónico permite releer la novela de Gutiérrez como un relato sobre "el buen morir" de Moreira, una vez que la novela se desembaraza del entramado argumental que justifica la historia. No otra cosa hacen los compadritos de Borges: pretenden "morir en su ley". Este "morir en su ley" es el predicamento ético socrático: sostener el propio modo de vida, aunque éste choque contra la ley estatal (ateniense). La ética es el arte del buen vivir. El Moreira airiano transforma (Zarathustra cimarrón: el mago de las transmutaciones) al gaucho del folletín en un personaje filosófico: no sólo porque da discursos (como Sócrates, como el personaje de Nietzsche), sino, especialmente, porque vive y muere en su ley.

El pasaje plagiado del Fedón es por demás significativo. Dice Moreira:

-Muchas veces, en el curso de mi vida he sentido que necesitaba, para purificarme, interpretar el sentido de ciertos sueńos, para el caso de que fuera esta clase de música la que me ordenaba hacer. El asunto fue así: con frecuencia en el transcurso de mi vida me visitó el mismo sueño, que se manifestaba en distintas visiones, según los casos, pero siempre diciendo lo mismo: "Haz música y practícala". Y en tiempos pasados yo suponía que se me estaba exhortando y estimulando en lo que hacía; así como se anima a los corredores, del mismo modo el sueño me estimulaba en aquello que ya estaba haciendo: componer música; dado que dedicarse al asesinato es la más grande música, y esto era lo que yo hacía. Ahora bien, después de que tuvo lugar el carnaval, y que la festividad del 22 de agosto me impidió morir, me pareció que, para el caso de que el sueńo me prescribiera crear música en el sentido vulgar de la palabra, no debía desobedecer, sino componer; y más seguro me pareció, en efecto, no marcharme antes de purificarme haciendo los poemas y obedeciendo de este modo al sueño. Así, en primer lugar, compuse en honor del dios a quien se consagraba la actual ceremonia; después de lo cual, por pensar que el poeta -si quiere llegar a ser poeta del todo- debe componer sobre la base de juegos de palabras y no de relatos determinados, y teniendo en cuenta que yo mismo no era inventor de mitos, compuse sobre la base de los primeros que encontré entre los de Sarmiento, que era los que tenía a mano y sabía de memoria (p. 25-26).

\section{Dice el Sócrates de Fedón:}

-Dile entonces la verdad, Cebes, respondió Sócrates, que no los he hecho con el propósito de competir con él, pues sabía que no sería fácil, sino en el intento 
de descifrar qué significaban ciertos sueños, y de purificarme, para el caso de que fuera esta clase de música la que me ordenaban hacer. El asunto fue así: con frecuencia en el transcurso de mi vida me visitó el mismo sueño, que se manifestaba en distintas visiones, según los casos, pero diciendo siempre lo mismo: "Haz música y practícala". Y en tiempos pasados yo suponía que se me estaba exhortando y estimulando en lo que hacía; así como se anima a los corredores, del mismo modo el sueño me estimulaba en aquello que ya estaba haciendo: componer música; dado que la filosofía es la más grande música, y esto era lo que yo hacía. Ahora bien, después de que tuvo lugar el juicio y que la festividad del dios me impidió morir, me pareció que, para el caso de que el sueño me prescribiera crear música en el sentido vulgar de la palabra, no debía desobedecer, sino componer; y más seguro me pareció, en efecto, no marcharme antes de purificarme haciendo los poemas y obedeciendo de este modo al sueño. Así, en primer lugar, compuse en honor del dios a quien se consagraba la actual ceremonia; después de lo cual, por pensar que el poeta -si quiere llegar a ser poeta del todo- debe componer sobre la base de mitos y no de cosas verdaderas, y teniendo en cuenta que yo mismo no era inventor de mitos, compuse sobre la base de los primeros que encontré entre los de Esopo, que eran los que tenía a mano y sabía de memoria (p. 88-89).

Aira modifica el inicio del parlamento de Sócrates para quitarle el vínculo con la respuesta a Fedón. Después, copia el texto platónico casi íntegro, modificando algunos pasajes clave: mientras la música que hace Sócrates es la filosofía, la de Moreira es el asesinato. El Moreira de Gutiérrez también canta. El de Aira concibe la música y el asesinato como un mismo arte bruto, popular, pura acción, hacer sin obra. El Moreira de Aira arguye que compone a partir de los "mitos de Sarmiento" (mientras que Sócrates lo hace a partir de las fábulas de Esopo), es decir, esa mitificación sobre la "naturaleza artística” del gaucho, su presunta aptitud para la música. El asesinato es de este modo un arte bruto, natural, tanto como el canto del gaucho con la guitarra. Mientras Sócrates afirma que el poeta "debe componer sobre la base de mitos y no de cosas verdaderas", Moreira dice que "debe componer sobre la base de juegos de palabras y no de relatos determinados", lo que, desde luego, caracteriza al propio texto. Estos juegos de palabras emparentan la prédica de Moreira con los procedimientos de Raymond Roussel y, desde luego, con los de Lamborghini.

El fragmento plagiado de Fedón (plagiado o intervenido, pues se puede pensar de los dos modos, como cuando Duchamp le pone bigotes a la Mona Lisa) es sugestivo: Sócrates, esperando su ejecución, y a pesar de que en otros diálogos platónicos como Ión, Apología de Sócrates y República la haya condenado, pasa sus días dedicado a la poesía. Las razones para este extraño comportamiento implican el desciframiento del sentido de ciertos sueños. La relación entre el sueńo y la poesía es antigua, aunque en Moreira 
parezca conectar con el onirismo del surrealismo y, de algún modo, responder a la clave de época, lacaniana. Ahora bien, para la poética de Aira, es más interesante el procedimiento de composición de Sócrates, ya que, al no saber escribir poesía, se limita a pasar las fábulas de Esopo a verso: se trata de un ejercicio duchampiano, una especie de ready-made o de traducción lamborghiniana. Entonces, Moreira encuentra en el Sócrates que espera su muerte un inesperado precursor de Breton y de Duchamp.

Hay otros pasajes del Fedón en los que no se puede hablar de reescritura sino más bien de traducción o versión. Desembarazado de la letra, Aira toma, de aquí y de allá, ideas platónicas y las despliega siguiendo esa "especie de escritura automática", o el procedimiento de la escritura frase-por-frase:

-Mis ideas empiezan con una caracterización de la muerte como un contrario decisivo a algunas actividades. Los filósofos suelen aplicar la muerte a la generación de relatos y descripciones: de lo general hacen series, algunas de ellas nos adormecen de felicidad, otras nos irritan (p. 46).

En el Fedón, Sócrates piensa la muerte como necesaria a la vida a partir de una hipótesis sobre la necesidad de los contrarios. Más todavía, la "generación" de cualquier cosa tiene lugar en su contraria: el origen del placer es el dolor, el del sueño la vigilia, etc., en un ciclo perpetuo. La muerte tiene su origen en la vida porque todo lo que vive tiene que morir, pero si todo muriera, razona Sócrates, las cosas terminarían por ser iguales (como si todo viviera): de modo que el vivir es un revivir, tiene su origen en la muerte. Desde luego, esta conjetura está sustentada en la teoría platónica de las Ideas. Lo que vive y muere es el cuerpo, mientras que el alma ni vive ni muere.

En esos mismos años también se estrena la versión fílmica de Leonardo Favio. En la escena de la novela en la que Moreira encuentra un proyector y pasa imágenes en la pared, volviéndose él mismo parte de la fantasmagoría, podría estar evocando la película (VILLANUEVA, 2005, p. 1177)7. Por supuesto que la versión de Favio acentúa el compromiso político de la época. En este contexto, transformar a Moreira en Sócrates, examinando la teoría platónica de la resurrección, parece no otra cosa que una provocación. Moreira es un ejercicio de libertad artística radical, en el que el onirismo de la historia parece contestar esa gravedad ilustrada de la izquierda de los setenta:

7 Suárez, refiriéndose al trabajo de Graciela Villanueva, precisa que el film de Favio se estrenó en mayo de 1973, pero que de todas maneras podría considerarse una alusión en la novela de Aira: "Si bien la obra está fechada el 31 de diciembre de 1972, las diversas alusiones al cine en el texto y el conocimiento público de la figura de Favio (en los medios de la época abundaban las notas que detallaban los avances y pormenores del rodaje), inducen a pensar, como sugiere Villanueva, que Aira utiliza la película como uno más entre los múltiples materiales que le sirven de base para contar su versión del mito" (SUÁREZ, 2014-2015, p. 231). 
-Cuando nińo, ciertas ópticas afinaron mi entendimiento. La constante observación de los efectos de la muerte a mi alrededor no podía dejar de infundirme algunas revelaciones: por ejemplo, la certeza de que no solo la muerte y la vida se diferenciaban por cuestiones cronológicas, sino por una oscura "cuestión de principios".

Luego, al crecer y observar que las modalidades de la producción y la lucha de clases eran responsables de la diferencia en la sociedad humana (y, según mi particular filosofía, en la Naturaleza), adquirí la certidumbre de que también eran responsables de la diferencia entre los vivos y los muertos (p. 51-52).

La oposición al materialismo como clave de época es, de nuevo, táctica. Pues la invención griega del Logos desemboca, insinúa el embrollado continuo de esta novela, en el marxismo convertido en exhortación. El pensamiento de las novelas de Aira, ese "movimiento de las ideas" (CONTRERAS, 2013, p. 187), se desprende de la razón, de la lógica, del principio de identidad y de no contradicción. Este Moreira onírico opta, en todo caso, por la inversión del platonismo atribuida a Nietzsche:

Bueno, así se pensaba entre ellos: incrédulos de los poderes definitivos de la razón, preferían el juego de transformaciones, de las preguntas y respuestas. ¿Quién era? ¿Qué era quién? En esas cáscaras (p. 66).

Moreira: rey de las metamorfosis (p. 77).

La literatura es, como lo sugiere el chancho en la secuencia en la que hablan los animales, suspensión de cualquier oposición metafísica:

- ¿Es la literatura una contradicción a las oposiciones -en general- que surgen del trabajo diario: construcción y emergencia de los hilos de los sistemas, por ejemplo el lenguaje; frente a un trabajo de moderación que imponen los otros discursos y frente a ellos las pruebas se transforman en catástrofes universales en las que encuentra la muerte sus analogías, y es como en los presocráticos una letra que ordena todo el edificio? (p. 50)

Moreira-Sócrates-Zarathustra. Escribe Lamborghini en Las hijas de Hegel: "De la razón, haberla y perdido" (LAMBORGHINI, 2013, p. 195). La literatura es esta pérdida de la razón, pues no se opone a ella (lo que reestablecería una oposición, propia de la metafísica) sino que cuenta con ella para perderse. Aira se queda con el "fantasma" de Moreira, el mito que sobrevive en los relatos, descartando esa concepción material de la literatura cuya irrisión es el pastiche de la novela, único en la obra: 
Los jóvenes conscriptos habían madrugado. Vieron acercárseles un armado fantasma. ¿Quién es? se preguntaban sus corazones. La literatura se encerraba entre sus alas oscuras, pues sus madres (que aún vivían) lees habían contado de noche mil veces los crímenes confusos del gaucho Moreira (p. 72).

Moreira no muere, porque nunca estuvo vivo, sino que más bien siempre sobrevive, es supervivencia. Moreira opta por el Pensamiento, por un espacio virtual en el que proyectar una imaginación libre, aunque regulada por la invención. El escritor-filósofo (el artista filósofo en términos de Nietzsche) opera con un material fantasmático, elusivo: la ficción es una especulación del pensamiento, no se concibe en términos de verdad o falsedad, sino de utilidad o inutilidad. Moreira es el mago de las transmutaciones, y la obra de Aira es imaginación en permanente transformación. Si la transmutación por antonomasia para Aira es la inversión, la elección de Zarathustra se justifica: la inversión del platonismo. En una época que, por el contrario, prestigia el materialismo, la novela airiana se arranca de la inversión de una inversión.

Lejos de los años 70, el materialismo es no obstante en nuestros días tanto el sentido común filosófico como el presupuesto ontológico de toda posición filosófica progresista, así como de la mayor parte de los pensamientos "post". Es posible que el origen borgiano de la obra de Aira deba tomar en cuenta esta toma de partido temprana por un peculiar idealismo. Muchos años después, Aira insiste con esta posición en Copi:

En esta dirección nos alejamos de la consideración "material" del texto o la obra de arte en general. Ese tipo de crítica me parece errónea y nefasta. La literatura es una actividad fantasmática, sin materialidad alguna (AIRA, 2003, p. 60).

Esta actividad sin materialidad está tematizada en las frecuentes apariciones de fantasmas en las novelas, así como también en el predominio de los espejismos ópticos y en general todo lo que implica la imaginación. Los monstruos que engendra la imaginación no son ni subjetivos ni objetivos o no podemos saberlo. Tal vez la célebre literatura mala, y el correlativo desdén por la escritura poética, implique una volatilización de la pesadez de la "prosa de calidad" y una restitución de la presencia fantasmal de la historia, de la fábula. Lo airiano implica entonces no un estilo de sintaxis o de dicción, sino una suerte de estilo de imaginación o de pensamiento.

La fusión Sócrates-Nietzsche en Moreira jugaría con esa trayectoria de la metafísica occidental: desde la invención del transmundo platónico hasta la exaltación del inframundo del materialismo marxista, el de los años setenta. El Moreira-Nietzsche es un héroe-escritor-filósofo en tanto restituye sus poderes a la ficción como invención de mundos absolutos. Los fantasmas, 
ficciones del pensamiento, ni remiten por semejanza a un mundo ideal, ni absolutizan al lenguaje en una remisión a sí mismo (el textualismo de los escritores de vanguardia de los setenta, en cualquiera de sus formas): no son apariencias porque no ocultan ninguna autenticidad. Los fantasmas son imágenes sin semejanza.

La famosa exhortación del Moreira airiano, "Sean marxistas", purificada de todo contenido utópico, adquiere la especificidad del procedimiento: si el plagio es la trasgresión a la propiedad legal del texto, constituye entonces el correlato artístico de los cuestionamientos marxistas en torno a la propiedad privada. Moreira es un ejercicio de trasgresión a toda ley o a la noción misma de ley. El gaucho malo como ready-made figura el efecto transformador de una acción anárquica que no puede reducirse ni a lo estético ni a lo político. Algo tiene de la exhortación de mayo del 68: la imaginación al poder. Pero también radicaliza una contestación cuya violencia no puede ser reivindicada por ninguna representación política: en ese sentido, escucha la admonición de El fiord. Solo en la literatura (o en el arte) la anarquía puede constituir un principio. La espectacularidad de Moreira, sus ribetes de manifiesto, la vuelven, retrospectivamente, y de modo paradójico, un programa anárquico, que irá encontrando en las novelas airianas de los años 80 su forma singular.

\section{Referencias}

AIRA, César. Moreira. Buenos Aires: Achával Solo, 1975.

AIRA, César. El vestido rosa. Las ovejas. Buenos Aires: Ada Korn, 1984.

AIRA, César. "Prólogo". En: Lamborghini, Osvaldo, Novelas y cuentos. Barcelona: Ediciones del Serbal, 1988: 7-16.

AIRA, César. Copi. Rosario: Beatriz Viterbo, 1991.

AIRA, César. "Ars narrativa". En: La ola que lee. Buenos Aires: Random House Mondadori, 2021.

AIRA, César. "La cifra". Conferencia leída en Homenaje a Jorge Luis Borges en Alianza Francesa de Buenos Aires, 1999. URL: https://revistaprause.blogspot. com/2019/10/la-cifra-cesar-aira.html

AIRA, César. Alejandra Pizarnik. Rosario: Beatriz Viterbo, 2004.

AIRA, César. La vida nueva. Rosario: Beatriz Viterbo, 2007.

BORGES, Jorge Luis. Ficciones. Obra Completas Tomo I. Buenos Aires, Emecé: 2007.

BORGES, Jorge Luis. El informe de Brodie. Obras Completas Tomo II. Buenos Aires: Emecé, 2008. 
CONTRERAS, Sandra. Las vueltas de César Aira. Rosario: Beatriz Viterbo, 2002.

CONTRERAS, Sandra. "Aira con Borges”. En: La Biblioteca, Buenos Aires, 2013, 184-201.

GUTIÉRREZ, Eduardo. Juan Moreira. Buenos Aires: Artes Gráfico Editorial Argentino, 2011.

LAMBORGHINI, Osvaldo. Novelas y cuentos I. Barcelona: Mondadori, 2013.

LUDMER, Josefina. El cuerpo del delito. Un manual. Buenos Aires: Eterna Cadencia, 2011.

MONTALDO, Graciela. "Borges, Aira y la literatura para multitudes". En: Boletín/6 del Centro de Estudios de Teoría y Crítica Literaria, Rosario, 1998, 7-17.

PELLER, Diego. Pasiones teóricas. Buenos Aires: Santiago Arcos, 2016.

PLATÓN. Fedón. Buenos Aires: Eudeba, 1971.

ROSA, Nicolás. "La escritura vil: los Lamborghini”. En: Relatos críticos. Cosas, animales, discursos. Buenos Aires: Santiago Arcos, 2006.

SUÁREZ, Nicolás. "Moreira en los setenta. Formas de la violencia y experiencias comunitarias", Cuadernos del Sur Letras N 44-45, Bahía Blanca, 2014-2015, 217-235.

STRAFACCE, Ricardo. Osvaldo Lamborghini, una biografía. Buenos Aires: Mansalva, 2008.

VILLANUEVA, Graciela. "Avatares de Moreira”. Revista Iberoamericana, Vol. LXXI, $\mathrm{N}^{\circ} 213,2005,1167-1178$.

Rafael Arce es Investigador del Consejo Nacional de Investigaciones Científicas y Técnicas (CONICET-Argentina) y Profesor de Literatura Argentina en la Universidad Nacional del Litoral (Santa Fe, Argentina). Ha publicado artículos sobre literatura argentina moderna y contemporánea. Es autor de los libros Juan José Saer: la felicidad de la novela y La visitación. Ensayo sobre la narrativa de Antonio Di Benedetto.

E-mail: rafael.arce@gmail.com 